\title{
Influence of age and sex on microRNA response and recovery in the hippocampus following sepsis
}

\author{
Asha Rani ${ }^{1}$, Jolie Barter ${ }^{1}$, Ashok Kumar ${ }^{1}$, Julie A. Stortz², McKenzie Hollen², Dina Nacionales ${ }^{2}$, \\ Lyle L. Moldawer ${ }^{2}$, Philip A. Efron², Thomas C. Foster ${ }^{1,3}$ \\ ${ }^{1}$ Department of Neuroscience, McKnight Brain Institute, University of Florida, Gainesville, FL 32611, USA \\ ${ }^{2}$ Department of Surgery, University of Florida, Gainesville, FL 32611, USA \\ ${ }^{3}$ Genetics and Genomics Program, University of Florida, Gainesville, FL 32611, USA
}

Correspondence to: Thomas C. Foster, Ashok Kumar; email: foster1@ufl.edu, kash@ufl.edu

Keywords: aging, sepsis, hippocampus, microRNA, sex dimorphism

Received: December 7, $2021 \quad$ Accepted: January 20, $2022 \quad$ Published: January 30, 2022

Copyright: (C) 2022 Rani et al. This is an open access article distributed under the terms of the Creative Commons Attribution License (CC BY 3.0), which permits unrestricted use, distribution, and reproduction in any medium, provided the original author and source are credited.

\begin{abstract}
Sepsis, defined as a dysregulated host immune response to infection, is a common and dangerous clinical syndrome. The excessive host inflammatory response can induce immediate and persistent cognitive decline, which can be worse in older individuals. Sex-specific differences in the outcome of infectious diseases and sepsis appear to favor females. We employed a murine model to examine the influence of age and sex on the brain's microRNA (miR) response following sepsis. Young and old mice of both sexes underwent cecal ligation and puncture (CLP) with daily restraint stress. Expression of hippocampal miR was examined in age- and sex-matched controls at 1 and 4 days post-CLP. Few miR were modified in a similar manner across age or sex and these few miR were generally associated with neuroprotection against inflammation. Similar to previous work examining transcription, young females exhibited a better recovery of the miR profile from day 1 to day 4, relative to young males and old females. For young males and all female groups, the initial response mainly involved a decrease in miR expression. In contrast, old males exhibited only upregulated miR on day 1 and day 4 and many of the miR upregulated on day 1 and day 4 were linked to neurodegeneration, increased neuroinflammation, and cognitive impairment. The results emphasize age and sex differences in epigenetic mechanisms that likely contribute to susceptibility or resilience to cognitive impairment due to sepsis.
\end{abstract}

\section{INTRODUCTION}

Sepsis is defined as life-threatening organ dysfunction caused by a dysregulated host immune response to infection [1-4]. Sepsis is surprisingly common with nearly two million hospital admissions annually in the United States, [2, 3, 5]. Furthermore, sepsis can induce immediate and persistent cognitive decline, with worse outcomes in older and Alzheimer's Disease and Alzheimer's Disease Related Dementia (AD/ADRD)diagnosed patients [6]. Of note, sepsis-induced neurocognitive pathology in patients without
AD/ADRD has been labeled sepsis-associated encephalopathy and is commonly seen in older adults [7]. In fact, sepsis has been labeled 'a disease of the aged,' as $60 \%$ of septic individuals are older than 65 years $[8,9]$. Greater than $50 \%$ of sepsis survivors suffer from cognitive dysfunction after hospital discharge, including issues with general memory, attention, verbal fluency, and executive function [10]. Also, a recent nationwide population-based study revealed that dementia is commonly present in a substantial proportion $(>11 \%)$ of adults $\geq 65$ years of age hospitalized with sepsis [11]. 
The response to sepsis and recovery from sepsis is influenced by age and sex. Examination of the molecular and physiological response to systemic inflammation in males indicates that diminished cogitation involves impaired synaptic function in the hippocampus, including microglial-mediated synapse elimination, early after a "cytokine storm" $[12,13]$. Following this initial response, young animals exhibit resilience and recovery of cognitive and synaptic markers, which may be absent with advanced age [1315]. Furthermore, there is a sexual dimorphism in response to sepsis with females exhibiting better outcomes $[16,17]$. Our recent work examining the hippocampal transcriptome in age and sex-matched controls (i.e., no sepsis day 0 ) and at 1 and 4 days post-cecal ligation and puncture (CLP) confirmed age and sex differences in gene expression [15]. In general, females were better able to resolve sepsis induced gene changes. In addition, older male mice exhibited a delayed and prolonged response to sepsis. Hypothesized mechanisms for age and sex related differences in the brain's response to sepsis include epigenetic regulation, with most of the work focused on DNA methylation [18-24].

Epigenetic regulation can also occur through microRNAs (miRs), a family of non-coding small RNAs that can post-transcriptionally regulate protein expression by inhibiting mRNA translation or promoting mRNA degradation [25]. Expression of miRs provides biomarkers of cellular senescence, aging phenotypes, and disease [26-29]. Indeed, many of the miRs involved in immune regulation are altered during aging [30]. While sexually dimorphic differences in brain miR have been described for development and stroke [31], little is known about the role of miR in mediating age and sex differences in the response to sepsis. To examine the role of miR in mediating age and sex differences, we characterized the expression of miR in the hippocampus on day 1 and day 4 after sepsis in young and aged male and female mice. In many cases, the tissue was from the same mice used to describe gene expression [15]. The miR expression results are consistent with mRNA expression in that females, particularly young females, resolve quickly and older males exhibit a prolonged response. Examination of the relationship between increased miR expression and mRNA in older males indicated little predictability for individual miR and mRNA on day 1, likely due to changes in a number of factors associated with fluctuating cytokines. In contrast, a decrease in mRNA expression was more likely on day 4 and linked to multiple miR, directed against specific mRNA. The results emphasize age and sex differences in examining the markers and mechanisms of the response and recovery from sepsis, as well as the need for precision/ personalized therapeutics to address post-septic cognitive decline.

\section{MATERIALS AND METHODS}

\section{Animals}

A schematic of the experimental paradigm is provided in Figure 1. All animal experiments were approved by the University of Florida Institutional Animal Care and Use Committee and followed Animal Research Reporting of In Vivo Experiments (ARRIVE) guidelines (https://www.nc3rs.org.uk/arrive-guidelines). The animals were cared for and used according to the Guide for the Care and Use of Laboratory Animals [32]. Young ( 4 months) and old ( 20 months) adult C57BL/6J (B6) mice of both sexes (young male $=12$; old male $=12$; young female $=12$; old female $=12$ ) were purchased from Jackson Laboratory (JAX; Bar Harbor, ME). Mice were cared for by the University of Florida Animal Care Services and housed in transparent cages (three to four animals of same sex/age per cage) under specific pathogen-free conditions in a single room. Animals were provided standard irradiated pelleted diet and water ad libitum for the duration of the

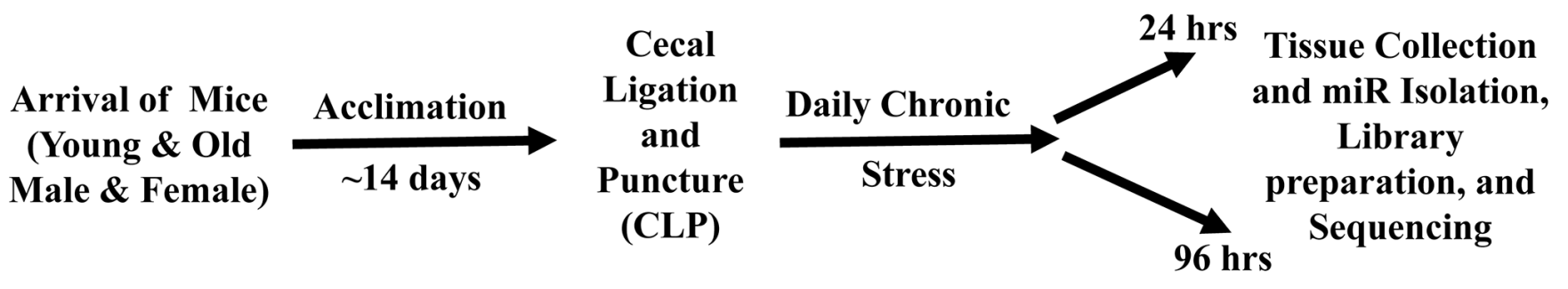

Figure 1. Schematic diagram of the experimental paradigm for sepsis induction, daily chronic stress (DCS), and tissue collection. Young adult ( 4 months) and old ( 20 months) male and female mice were purchase from Jackson Laboratory (JAX Bar Harbor, ME). Prior to initiation of the experiment, mice were acclimated to a 12-hour light-dark cycle for a minimum of 14 days. Sepsis was induced by employing cecal ligation and puncture (CLP) under isoflurane anesthesia. DCS was conducted by placing mice in weighted plexiglass animal restraint holders (Kent Scientific; Torrington, CT) for 2 hours daily commencing the day after CLP. Mice were euthanized for tissue collection either 24 or 96 hours post CLP+DCS. The hippocampus was dissected, flash frozen, and stored at -80 , for miR isolation and sequencing. 
study. Prior to initiation of the experiment, mice were acclimated to a 12-hour light-dark cycle for a minimum of 14 days. Due to the coprophagic nature of mice, this assured that mice in the same cage would have similar microbiota composition and structure [33]. Only animals of the same sex, age, and treatment group were housed together.

\section{Intra-abdominal sepsis and daily chronic stress model}

In order to recapitulate the human condition of abdominal sepsis, a murine model of sepsis and persistent inflammation, previously described by our laboratory, was utilized [34]. Briefly, general anesthesia was induced with inhaled isoflurane and CLP was performed via a midline laparotomy with exteriorization of the cecum to induce a model of sepsis. The cecum was ligated with 2-0 silk suture $1 \mathrm{~cm}$ from its tip, a 25 -gauge needle was used to puncture the cecum, and the laparotomy was closed in one layer with surgical clips. Buprenorphine analgesia was provided for 48 hours post-surgery. Imipenem monohydrate $(25 \mathrm{mg} / \mathrm{kg}$ in $1 \mathrm{~mL} \quad 0.9 \%$ normal saline) was administered subcutaneously 2 hours post-CLP and then continued twice daily for 72 hours. Subsequently, we added a component of daily chronic stress (DCS). DCS was conducted by placing mice in weighted plexiglass animal restraint holders (Kent Scientific; Torrington, CT) for 2 hours daily commencing the day after CLP. DCS was combined with CLP (CLP+DCS) to mimic the stress that occurs in patients when residing in an intensive care unit and better reflects human sepsis relative to CLP alone [34, 35]. This model was previously used to describe age and sex-related changes in hippocampal transcription [15]. The CLP+DCS mice, along with mixed-sex naïve mice (no CLP, no DCS, no antibiotics, and no fluid resuscitation) were euthanized on day 1 or 4 post-CLP+DCS. Mice were anesthetized with isoflurane (Halocarbon Laboratories, River Edge, NJ) and swiftly decapitated.

The work consisted of young and old female $(50 \%)$ and male $(50 \%)$ mice. Of note, the last restraint stress occurred 1 hour prior to sacrifice, and mice that were sacrificed 24 hours after CLP received restraint cone stress 1 hour prior to sacrifice.

\section{Tissue collection}

Animals were sacrificed either 24 hours or 4 days following CLP. Age and sex-matched control groups were sacrificed directly from the home cage, without receiving surgery or anesthesia. Mice were anesthetized with isoflurane (Halocarbon Laboratories, River Edge, NJ) and swiftly decapitated. The brains were rapidly removed and the hippocampi were dissected. All brain samples were flash frozen in liquid nitrogen and were stored at $-80^{\circ} \mathrm{C}$. One whole hippocampus was used for microRNA sequencing. In some cases, the other hippocampus was used for mRNA sequencing and the results have previously been reported [15].

\section{RNA isolation}

Hippocampus tissue miR was isolated using mirVana miR Isolation Kit (ThermoFisher Scientific, Cat\# AM1560) according to the manufacturer's instructions. The quantity and quality of the RNA was determined by University of Florida Interdisciplinary Center for Biotechnology Research using the Agilent RNA 6000 Pico Kit to determine the concentration of total RNA, and a Small RNA Kit was used to measure the concentration of tissue micro RNA (miR) on the Agilent Bioanalyzer instrument (Agilent Technologies).

\section{Small RNA library preparation and sequencing}

To perform miR profiles, sequencing libraries were prepared using 48 samples (old and young adult males and females) of 12 different groups. For males, examination of miR expression was performed for the same mice in which the mRNA response was examined and included young male control $(n=4 / 4$, $\mathrm{miR} / \mathrm{mRNA}$ ), young male 24 hours post-sepsis ( $n=$ $4 / 4)$, young male 4 days post-sepsis $(n=4 / 4)$, old male control $(n=4 / 4)$, old male 24 hours post-sepsis $(n=$ $4 / 4)$, old male 4 days post-sepsis $(n=4 / 4)$. For females, most of the miR samples were from the same mice in which mRNA expression was measured, particularly for older females. However, due to loss of tissue, some younger females were replaced: young female control ( $n=4 / 2, \mathrm{miR} / \mathrm{mRNA})$, young female 24 hours post-sepsis $(n=4 / 1)$, young female 4 days post-sepsis $(n=4 / 3)$, old female control $(n=4 / 4)$, old female 24 hours post-sepsis $(n=4 / 4)$, and old female 4 days post-sepsis $(n=4 / 3)$. Methods for miR library preparation and sequencing have previously been published [28, 36, 37]. Briefly small RNA libraries were prepared using the Ion Total RNA-Seq Kit v2 (Thermo Fisher, catalog number 4475936). Each library was barcoded with Ion Xpress RNA SeqBarcode 01-16 Kit (ThermoFisher, Cat\# 4475485) to enable multiplex sequencing. The concentration of the libraries was quantified by the Qubit dsDNA HS Assay (Thermo Fisher, Cat\# Q32851). In addition, the size distribution and molar concentration was determined with the High Sensitivity D1000 Screen Tape Kit (5067-5584) on 2200 TapeStation system (Agilent Technologies, Cat\#G2964A) according to the manufacture's protocol. 


\section{Data acquisition, bioinformatics and statistical analysis}

Data acquisition and analysis for miR expression was performed as previously described [28, 36, 37]. In brief, on Partek Flow server FASTQ files were trimmed and aligned to the mouse (mm10) genome using Bowtie (version 1.0.0). Normalization was performed on total counts in Partek and genes with an average total count of less than 5 were removed, consistent with our previously published work [28, 36-39]. Statistical filtering was performed using a $p$-value set at $p<0.05$. Features list that passed the statistical filter were then separated into upregulated or downregulated based on fold change. The data for this study has been uploaded to the Gene Expression Omnibus under the accession number GSE188874.

\section{RESULTS}

Figure 2 illustrates the global pattern of differentially expressed miRs (DEmiRs) in young and old adult male and female mice, specifically 1 or 4 days following sepsis compared to sex and age-matched controls. In general, females and older animals exhibited a more robust response on day 1, with an increased number of DEmiR. Interestingly, the largest changes were for downregulated miR with the exception on older males, which exhibited only up regulated miR. Young females exhibited considerable recovery on day 4 , observed as a marked decrease in the number of DEmiR. For the other groups, there was an increase in DEmiR on day 4, mainly for upregulated miR, except for older females, which exhibited increased expression of up and downregulated $\mathrm{miR}$. The increase in upregulated $\mathrm{miR}$ was particularly robust for older males, which exhibited the greatest number of upregulated miR on day 1 and day 4 .

\section{Young adult male mice}

On day 1 following sepsis, young males exhibited 11 downregulated miRs compared to controls, in the absence of upregulated miR (Figure 2). On day 4 following sepsis, the number of downregulated miRs increased to 30 and included 2, miR-335-3p and miRlet-7d-3p, which were also decreased on day 1 . Expression of miR-let-7d-3p has been linked the regulation of the inflammatory response $[40,41]$ and expression of miR-335-3p has been linked to the response to stress [42] and regulation of neuroprotection and neurodegeneration [43, 44]. In addition, elevated expression of miR-335-3p has been associated with poorer memory during aging [45] and inhibition of estrogen receptor expression [46]. Upregulation was observed for 24 miRs on day 4 .

\section{Old adult male mice}

In contrast to young males, the response in old males was limited to up regulation of miRs for both day 1 and day 4. For older males, 36 miRs were upregulated on day 1 and the number of upregulated miRs increased to 62 on day 4 , with 22 increased on both days, relative to controls (Table 1). Three of the miRs upregulated on days 1-4 (miR-223-3p, miR-98-3p, miR-662-5p) are linked to the X-chromosome. Examination of the pattern of expression for these 22 miRs indicated that 19 continued to increase from day 1 to day 4. Although expression was above baseline, 3 miRs exhibited evidence of returning towards baseline. No miRs were affected in the same direction on day 1 in young and

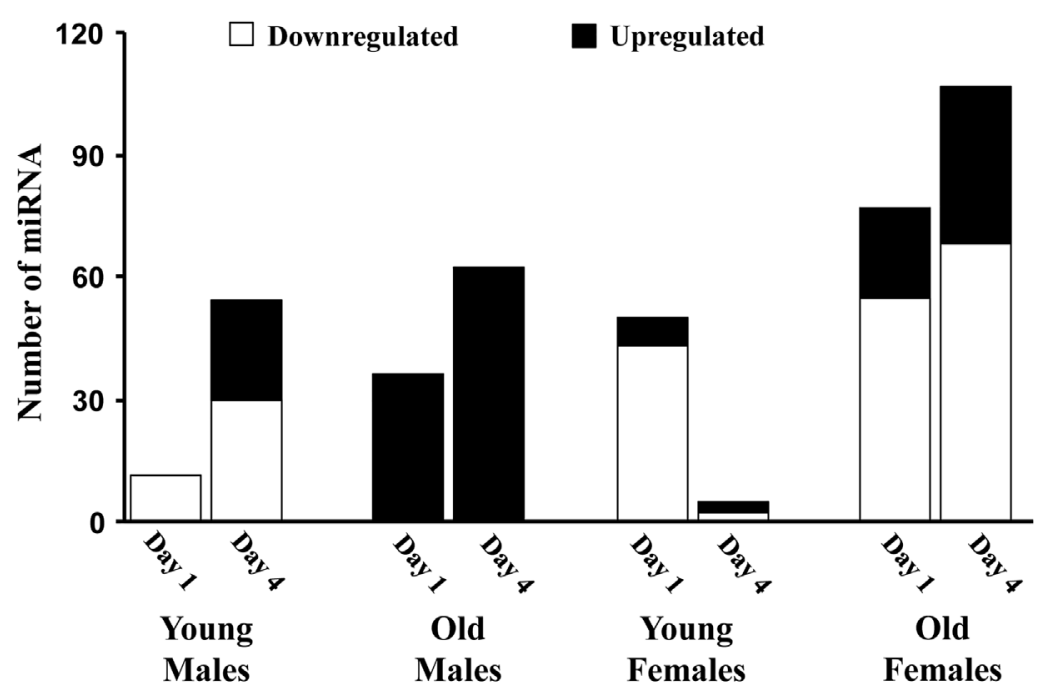

Figure 2. The number of miRs differentially expressed for each age and sex group. Summary of the total number of miRs increased (black) or decreased (white) expression in the hippocampus 1 or 4 days after sepsis relative to age-matched controls. 
Table 1. Mean \pm SEM fold change, relative to the mean of old control males, for normalized counts of 22 miRs that increased expression on day 1 and day 4 of sepsis in old males.

\begin{tabular}{lccc}
\hline miR & Day 1 & Day 4 & Change Day 1 to Day 4 \\
\hline mmu-miR-381-3p & $1.40 \pm 0.04$ & $1.46 \pm 0.09$ & up \\
mmu-miR-872-3p & $1.45 \pm 0.09$ & $1.63 \pm 0.24$ & up \\
mmu-let-7f-1-3p & $1.51 \pm 0.23$ & $1.39 \pm 0.12$ & down \\
mmu-miR-7a-1-3p & $1.52 \pm 0.07$ & $1.49 \pm 0.17$ & down \\
mmu-miR-212-3p & $1.52 \pm 0.10$ & $1.58 \pm 0.23$ & up \\
mmu-miR-31-3p & $1.60 \pm 0.07$ & $1.59 \pm 0.19$ & down \\
mmu-miR-30b-5p & $1.61 \pm 0.15$ & $2.10 \pm 0.35$ & up \\
mmu-miR-342-3p & $1.61 \pm 0.09$ & $1.76 \pm 0.31$ & up \\
mmu-miR-323-3p & $1.64 \pm 0.11$ & $1.86 \pm 0.46$ & up \\
mmu-miR-223-3p & $1.65 \pm 0.26$ & $2.50 \pm 0.70$ & up \\
mmu-miR-672-3p & $1.66 \pm 0.25$ & $2.17 \pm 0.41$ & up \\
mmu-miR-15a-5p & $1.71 \pm 0.13$ & $1.53 \pm 0.19$ & down \\
mmu-miR-30c-5p & $1.72 \pm 0.19$ & $1.99 \pm 0.18$ & up \\
mmu-miR-33-3p & $1.72 \pm 0.13$ & $1.53 \pm 0.12$ & down \\
mmu-miR-15b-5p & $1.74 \pm 0.03$ & $1.87 \pm 0.43$ & up \\
mmu-miR-98-3p & $1.80 \pm 0.35$ & $1.65 \pm 0.19$ & down \\
mmu-miR-106b-5p & $1.82 \pm 0.15$ & $1.90 \pm 0.30$ & up \\
mmu-miR-340-5p & $1.84 \pm 0.16$ & $2.82 \pm 0.94$ & up \\
mmu-miR-672-5p & $1.85 \pm 0.37$ & $2.82 \pm 0.99$ & up \\
mmu-miR-467e-5p & $1.96 \pm 0.37$ & $1.68 \pm 0.36$ & down \\
mmu-miR-190a-3p & $1.97 \pm 0.18$ & $2.05 \pm 0.34$ & up \\
mmu-miR-362-5p & $2.80 \pm 0.58$ & $3.88 \pm 0.72$ & up \\
\hline
\end{tabular}

older males. There were 6 miRs that exhibited an increase on day 4 , in young and old septic males. These miRs have been linked to inhibition of inflammation and neuroprotection (miR-223-3p, miR-544-5p, miR219a-5p, miR-15a-5p) [47-54] and neural development and cognition (miR-190a-3p, miR-344-3p) [55, 56]. In addition, 5 miRs, which were increased in older males on day 4 , exhibited downregulation in young males on day 4. Again, these miRs are associated with neuroprotection and reduced neuroinflammation, including let-7c-5p [57]. However, upregulation of let-7b-5p [58, 59] and let-7a-5p [60] in older males may be markers of metabolic stress consistent with a delayed/prolonged response in older males during a time when younger animals are exhibiting resolution of inflammation.

\section{Young adult female mice}

For young females on day 1 following sepsis, the number of DEmiRs was approximately 5 fold more than young male; however, like males, most of the miRs, 43 out of 50, were downregulated (Figure 2). In addition, while young males exhibited an increased number of
DEmiRs on day 4, young females exhibited a reduced number of DEmiRs on day 4 (3 upregulated and 2 downregulated), consistent with increased rate of recovery for young females over this time period [15]. The DEmiRs for young females were not common across days, such that no miRs exhibited a similar directional change on day 1 and day 4 . Furthermore, the DEmiRs were not the same as that observed for young males, with no common up or downregulated miRs on day 1 and only two miRNAs (miR-383-5p, miR-1249$3 p$ ) were downregulated on day 4 in both young females and young males. Downregulation of miR-383-5p may provide a neuroprotection against inflammation and associated oxidative stress [61]. Thus, for young animals, the initial response on day 1 is mainly a downregulation of miRs; although the specific miRs differ across sex, suggesting a sexually dimorphic response to sepsis. Furthermore, young females exhibited considerable recovery from day 1 to day 4 .

\section{Old adult female mice}

Similar to the age comparison for young and old males, older females were more responsive than young 
Table 2. Mean \pm SEM fold change, relative to the mean of old control females, for normalized counts of 18 miRs that decreased expression on day 1 and day 4 of sepsis in old females.

\begin{tabular}{lccc}
\hline miR & Day 1 & Day 4 & Change Day 1 to Day 4 \\
\hline mmu-miR-320-3p & $0.44 \pm 0.05$ & $0.71 \pm 0.10$ & up \\
mmu-miR-383-5p & $0.53 \pm 0.05$ & $0.65 \pm 0.12$ & up \\
mmu-miR-135b-5p & $0.54 \pm 0.06$ & $0.53 \pm 0.01$ & down \\
mmu-miR-495-5p & $0.57 \pm 0.01$ & $0.57 \pm 0.11$ & down \\
mmu-miR-409-5p & $0.60 \pm 0.06$ & $0.57 \pm 0.04$ & down \\
mmu-miR-129-2-3p & $0.63 \pm 0.06$ & $0.55 \pm 0.02$ & down \\
mmu-miR-322-5p & $0.63 \pm 0.06$ & $0.35 \pm 0.02$ & down \\
mmu-miR-377-5p & $0.64 \pm 0.04$ & $0.50 \pm 0.09$ & down \\
mmu-miR-671-5p & $0.65 \pm 0.10$ & $0.72 \pm 0.16$ & up \\
mmu-miR-370-3p & $0.66 \pm 0.05$ & $0.65 \pm 0.10$ & down \\
mmu-miR-324-5p & $0.68 \pm 0.05$ & $0.72 \pm 0.11$ & up \\
mmu-miR-125b-1-3p & $0.71 \pm 0.06$ & $0.73 \pm 0.06$ & up \\
mmu-miR-135a-5p & $0.31 \pm 0.03$ & $0.30 \pm 0.03$ & down \\
mmu-miR-130a-3p & $0.39 \pm 0.03$ & $0.33 \pm 0.08$ & down \\
mmu-miR-873a-3p & $0.39 \pm 0.04$ & $0.41 \pm 0.06$ & up \\
mmu-miR-26b-5p & $0.48 \pm 0.01$ & $0.66 \pm 0.10$ & up \\
mmu-miR-140-5p & $0.56 \pm 0.04$ & $0.61 \pm 0.03$ & up \\
mmu-miR-99b-3p & $0.60 \pm 0.08$ & $0.65 \pm 0.07$ & up \\
\hline
\end{tabular}

females, on day 1 after sepsis, exhibiting 22 upregulated and 55 downregulated miRs (Figure 2). Three miRs were upregulated in young and older females on day 1 (miR-190a-3p, miR-let-7a-1-3p, miR-3085-3p). Interestingly, miR-190a-3p, which is neuroprotective $[62,63]$ was also upregulated in old males on day 1 and both young and old males on day 4 . miR-let-7a is induced by systemic inflammation and regulated by estradiol [64]. Seven miRs were downregulated on day 1 in both young and old females (miR-127-3p, miR222-3p, miR-299a-3p, miR-221-3p, miR-337-5p, miR$541-5 \mathrm{p}$, miR-652-3p). Three are linked to the $\mathrm{X}$ chromosome (miR-222-3p, miR-221-3p, miR-652-3p). In this case, downregulation has been linked to reduced inflammation (miR-222-3p, miR-221-3p) [65-69]. Thus, on day 1 following sepsis, the expression of miR in young and old females is suggestive of process for neuroprotection and reduced inflammation. No miRs were common for young and old females on day 4, likely due to the considerable recovery of young females.

For both day 1 and day 4 for older females, $18 \mathrm{miRs}$ were downregulated (Table 2) and $3 \mathrm{miRs}$ were upregulated (miR-669b-5p, miR-5121, miR-542-3p). For the downregulated miRs, nine continued to decrease on day 4, while 9 exhibited a return towards baseline. When comparing older males and older females, older females exhibit mainly downregulation of miR on day 1 and day 4, and older males exhibited only upregulated miR. Across the two groups, five miRs (miR-190a-3p, let-7a1-3p, miR-362-5p, miR-31-3p, miR-7b-3p) were up regulated on day 1 in older males and older females. Five different miRs (miR-30c-5p, miR-30b-5p, miR143-3p, miR-384-5p, miR-380-3p) were up regulated on day 4 across all older animals.

\section{Relationship between increased miR and mRNA}

Theoretically, expression of miR and associated mRNA should be inversely correlated. In this case, we would expect that for the $22 \mathrm{miRs}$ that increased 1-4 days following sepsis in old males, the associated mRNA should exhibit decreased expression. We used mRNA expression previously reported [15] for the same older male animals $(n=12)$, to determine if genes that were significantly $(p<0.05)$ upregulated or downregulated on day 1 and day 4 , were associated with the $22 \mathrm{miR}$ that were increased on both days. The predicted mRNA for each of the 22 miRs was obtained using mirWalk database [70].

Using the previously reported mRNA expression of older males [15], the percent of significantly $(p<0.05)$ differentially expressed genes, linked to each of the 22 miRs within each category (day 1 up 496 genes, day 1 down 701 genes, day 4 up 2932 genes, day 4 down 3508 genes) were determined (number of associated 
DEGs/total number of significant genes in each category) (Figure 3). The percent of DEGs associated with the miR was greatly increased on day 4 . Due to differences in the number of DEGs, we might predict that the proportion linked to the miR would increase from upregulated to downregulated on day $1(701 / 496=$ 1.41) and on day 4 relative to day 1 upregulated (day 4 up 2932/496 = 5.91; day 4 down 3508/496 = 7.07). However, relative to upregulated genes on day 1 , the percent of day 4 upregulated mRNA was $63 \%$ of predicted (13.2 observed/20.7 predicted) and the downregulated mRNA was $120 \%$ of predicted (29.7 observed/24.7 predicted) (Figure 3). The results indicate that the expected decrease in mRNA expression associated with increased miR expression was more prominent on day 4.

A mismatch between expression of miR and mRNA is likely due to other transcriptional regulators, including the downregulation of repressor genes that would normally inhibit transcription [71, 72]. The ability of $\mathrm{miR}$ to inhibit gene expression maybe enhanced by an increase in the number of different miR that bind the specific mRNA of interest. To examine the effect of increasing number of different miRs that target individual genes, we examined how many of the $22 \mathrm{miR}$ that were upregulated over days 1-4 in older males, targeted each gene that exhibited a significant increase or decrease in expression (Figure 4A). Most ( $>50 \%)$ of the mRNAs were associated with 1-2 miR. However, by day 4 , there was a marked increase in the proportion of mRNA that exhibited decreased expression, which were associated with multiple $(>2)$ miRs. Thus, the proportion of decreased mRNA associated with 3 or more miR went from $37 \%$ on day 1 to $49 \%$ on day 4 (Figure 4B). Together, the results suggest that by day 4, multiple miR appear to gain increasing control over expression of individual mRNA.

\section{DISCUSSION}

Variability in cognitive decline during aging is associated with genetic factors, including sex, and environmental factors, including the history of severe inflammation, that act through epigenetic mechanisms to modify the trajectory of cognitive decline $[14,25$, 73]. Sex differences are observed for the response and recovery of brain damage, infectious diseases, and aging [15, 31, 74-76], possibly due to sex steroids, sex chromosomes, and epigenetic differences. Our previous work indicates sex and age differences in the hippocampal transcriptional response and recovery from sepsis [15]. The current study indicates a similar pattern of expression for miR. Over all, females were the most responsive group on day 1. In particular, females exhibited more miR downregulated on day 1 and several were common in young and old females. Several common miRs, which were downregulated on day 1 in young and aged females, are located on the $\mathrm{X}$-chromosome and have been reported to regulate inflammation including miR-222-3p [65, 77], miR221-3p [69, 78-80], and miR-652-3p [81]. In contrast, older males exhibited increased expression of three different X-chromosome miR (miR-223-3p, miR-98-3p,

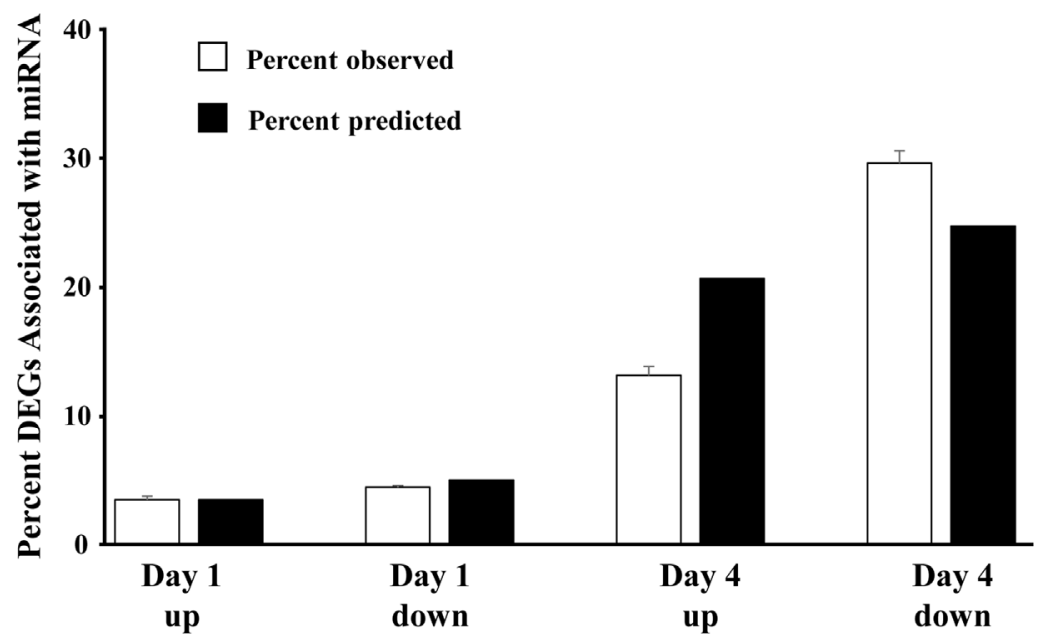

Figure 3. Direction of mRNA expression associated with increased miR expression on day 1 and day 4 post-sepsis. The open bars represent the mean + SEM percent of total differentially expressed genes, associated with the 22 miRs that increased in older males on day 1 and day 4, for each category (Day 1 and Day 4 up and downregulated genes). The filled bars represent the percent of differentially expressed genes, relative to day 1 upregulated, which are expected due to an increase in the total number of differentially expressed genes. Note that for day 4, the percent of upregulated differentially expressed genes is $68 \%$ of predicted and the percent of downregulated differentially expressed genes is $120 \%$ of predicted, suggesting that upregulated miRs are gaining control (i.e., downregulating) the associated mRNA. 
miR-662-5p). In this case, an increase in miR-223-3p appears to protect against inflammation [47-49]. Antiinflammatory properties of the sex steroid, estrogen, may contribute to the sexually dimorphic response to inflammation and sepsis and sepsis induced changes in miR may reflect a role for estrogen in recovery from inflammation. For example, young males exhibited downregulation of miR-335-3p on day 1 and day 4, which could enhance expression of estrogen receptor alpha [46]. Similarly, on day 1 young and older females exhibited upregulation of miR-222-3p which could increase estrogen receptor alpha expression [82]. On day 4 , young and older males exhibited increased expression of miR-15a-5p, which may regulate estrogen signaling [83]. Indeed, for the $22 \mathrm{miRs}$ that were increased on day 1 and day 4 in older males, several (miR-30b-5p, miR-342-3p, miR-30c-5p, miR-106b-5p, miR-672-5p) have been linked to estrogen responsiveness [84-88].

The marked decrease in miR expression on day 1 may suggest a level of baseline control of gene expression by $\mathrm{miR}$, which is rapidly altered during the cytokine storm. In contrast, the upregulated miR was more prominent on day 4 in males and older females. Relatively few miRs were altered in the same direction across days

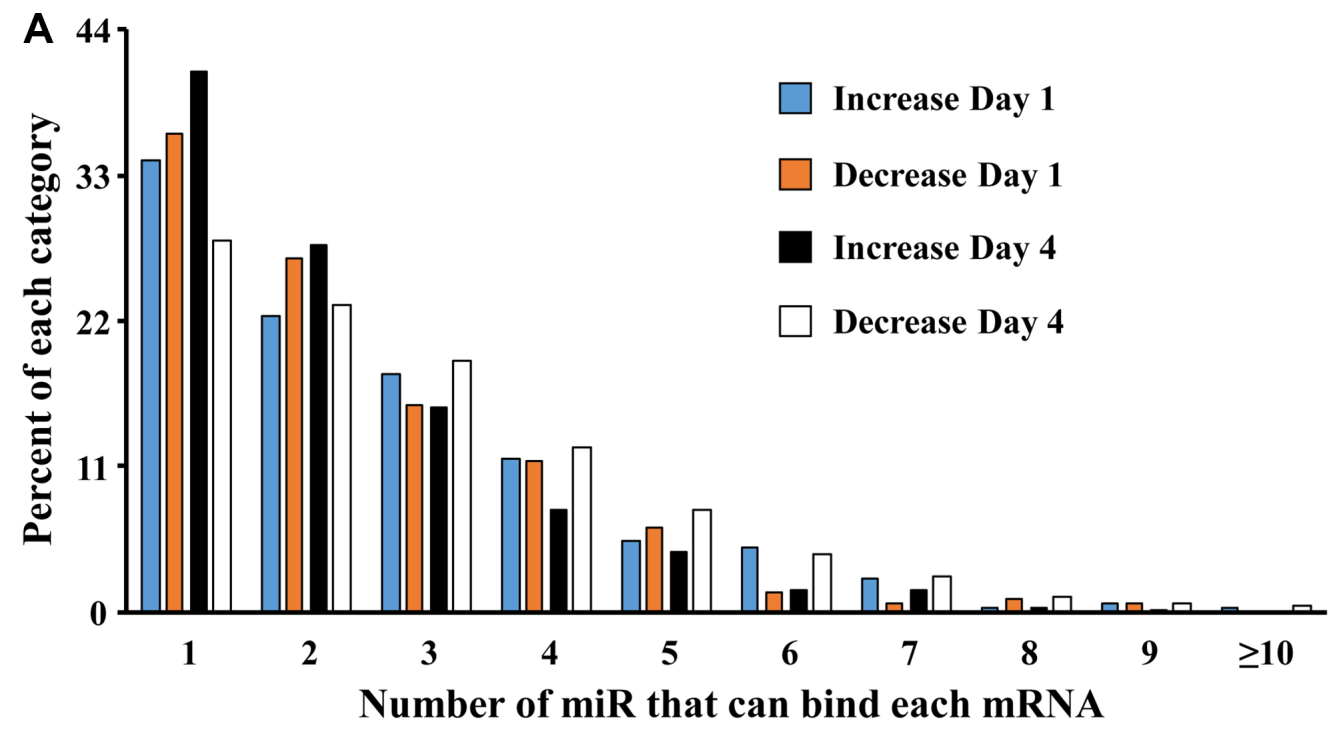

B

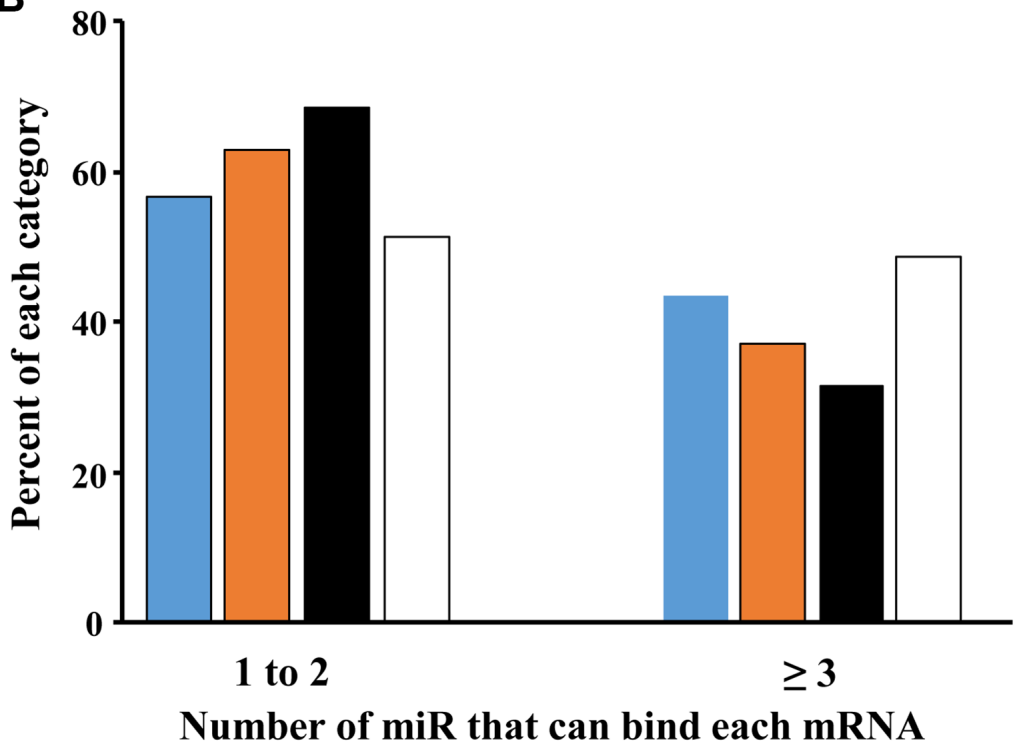

Figure 4. Increasing the number of miRs associated with an individual gene promotes mRNA downregulation. (A) Each bar represents the proportion of mRNAs (y-axis) that were upregulated on day 1 (blue bar) and day 4 (orange bar) or downregulated on day 1 (black bar) and day 4 (white bar) and were associated with 1 to $\geq 10$ of the 22 miRs ( $x$-axis) that increase in older males. (B) Collapsing the data to show that the percent of gene expression associated with 1-2 or $\geq 3$ miRs. Note that on day 4 , mRNA associated with $\geq 3$ miRs are more likely to be downregulated. 
Table 3. A summary of biological functions related to neuroinflammation, neuroprotection, neurodegeneration, and cognition for some of the $\mathbf{2 2}$ miRs, which were increased in older male mice.

\begin{tabular}{ll}
\hline miR & Role in neuroinflammation, neuroprotection, neurodegeneration, and cognition \\
\hline miR-106b-5p & Upregulated during neuroinflammation and neurodegenerative disease models [105-109] \\
miR-15a-5p & Can have pro- or anti-apoptotic activity [53,54, 110] \\
miR-15b-5p & Can have pro- or anti-apoptotic activity [110-113] \\
miR-190a-3p & Biomarker for postoperative cognitive dysfunction [55] \\
miR-212-3p & Downregulation is a biomarker for neurodegenerative disease [114-116] \\
miR-223-3p & Inhibition of neuroinflammation [47-49, 117]. Biomarker of sepsis severity [102] \\
miR-30b-5p & Upregulation is neuroprotective [118-120] \\
miR-30c-5p & Can have pro- or anti-apoptotic activity [121-123] \\
miR-31-3p & Role in conditioned place preference [124] \\
miR-323-3p & Biomarker for cognitive impairment [125, 126] \\
miR-33-3p & Neurogenesis [127] \\
miR-340-5p & Anti-inflammatory and neuroprotective [128-130] \\
miR-342-3p & Upregulated in neuroinflammation and neurodegenerative disease models [131-135] \\
miR-362-5p & Nervous system development [136] \\
miR-381-3p & Upregulation during encephalomyelitis [137] and HIV associated with cognitive impairment [138] \\
miR-7a-1-3p & Promotes generation of oligodendrocytes [139] and regulates excitatory synaptic transmission [140] \\
let-7f-1 & Promotes IL-6 secretion in activated macrophages [141] \\
miR-98-3p & Upregulated by caloric restriction [142] \\
\hline
\end{tabular}

and were mainly limited to older animals. Again, differences across days may relate to the time course of the cytokine levels (i.e., cytokine storm) and the ability to recover from infection. For older females, $18 \mathrm{miRs}$ were decreased on day 1 and day 4; however, half the miR exhibited evidence of recovery with expression moving towards baseline from day 1 to day 4, consistent with better recovery of females.

Very few miRs were similarly modified across age or sex, particularly for day 1 . For some miRs that were consistently downregulated in young males on day 1 and day 4 (miR-let-7d-3p) or downregulated in young males and females on day 4 (miR-383-5p), previous research suggest that downregulation is neuroprotective against inflammation and associated oxidative stress [41, 42, 61]. Similarly, for miRs that exhibited an increase on day 4 , in young and old septic males (miR223-3p, miR-544-5p, miR-219a-5p, miR-15a-5p), the increased expression has been linked to inhibition of inflammation and neuroprotection [47-54]. Three miRs were upregulated in young and older females on day 1 (miR-190a-3p, let-7a-1-3p, miR-3085-3p). Increased expression of let-7a-1-3p [89] is associated with reduced inflammation following spinal cord injury. Increased miR-3085-3p may be responsible for the early inhibition of $\mathrm{NF} \kappa \mathrm{B}$ signaling [90]. Interestingly, miR$190 \mathrm{a}-3 \mathrm{p}$, which is neuroprotective [62, 63], exhibited increased expression across sexes, in that it was also upregulated in old males on day 1 and both young and old males on day 4. In contrast, three of the five miRs that were up regulated on day 4 across older male and female animals (miR-143-3p, miR-380-3p, miR-384$5 p)$ may contribute to neurotoxicity [91-96].

Severe systemic inflammation is a negative modifier of the trajectory of cognitive decline [14, 97]. Furthermore, elderly patients are more likely to suffer cognitive impairment after sepsis-associated encephalopathy [6, 7]. Epigenetic changes over the course of aging or due to the history of infection can either prime the brain to respond to immune stimulation or result in immune tolerance [14, $98,99]$. In this way, epigenetics regulates transcriptional responsiveness and susceptibility or resilience to stressors of aging, including systemic inflammation $[14,25,100$, 101]. Table 3 provides a summary of biological functions related to neuroinflammation, neuroprotection, neurodegeneration, and cognition for some of the 22 miRs, which were increased in older male mice, and may contribute to differences in transcription and susceptibility or resilience to cognitive impairment. For example, age-related differences in cognitive impairment, associated with systemic infection, are linked to decreased transcription of hippocampal synaptic genes and an altered transcriptional response to inflammation [13-15]. Thus, the increase in miR-7a-1-3p, miR-33-3p, and miR-362-5p may contribute to decreased expression of neuronal/glial and synaptic genes; while miR-15a-5p, 
miR-15b-5p, and miR-30c-5p may influence the expression of apoptotic genes observed in older males on day 4 [15]. Nevertheless, for most of the miRs, increased expression is linked to neurodegenerative disease, increased neuroinflammation, and cognitive impairment (Table 3) consistent with enhanced vulnerability of older brains. However, increased expression of miR-223-3p, miR-340-5p, and miR-30b-5p has been linked to antiinflammatory neuroprotection, suggesting possible resilience mechanisms that may preserve cognition in the face of neuroinflammation $[73,100]$.

One question we attempt to address is whether the increase in miR expression on day 1 and day 4 in older males contributes to the observed change in mRNA expression. Theoretically, expression of $\mathrm{miR}$ and associated mRNA should be inversely correlated. For the 22 miRs that increased on day 1 and day 4 in older males, the likelihood that the associated mRNA was increased or decreased was equivalent on day 1 . In contrast, an increased propensity for mRNA to exhibit downregulation was evident on day 4 . The decrease in mRNA on day 4 may relate to the fact that most of the 22 miRs continued to increase expression from day 1 to day 4. Interestingly, downregulation of mRNA was largely observed for genes, which interact with multiple miRs. The absence of a negative correlation between individual miR and associated mRNA on day 1 may be due other transcriptional regulators activated during or immediately after the cytokine storm associated with sepsis. Previous work suggests that despite an increase in miR, expression of associated mRNA may be increased, rather than decreased, due to ongoing activation of transcription factors or the downregulation of repressor genes, which would normally inhibit transcription [71, 72]. On day 4, upregulated miR in older males appears to gain influence on mRNA expression. In particular, decreased expression is observed for mRNA that can be bound by multiple upregulated miRs.

The molecular mechanisms that underlie age and sex differences in response to inflammation, disease, brain damage, and aging are not fully understood. The results emphasize age and sex differences in epigenetic mechanisms that may contribute to differences in vulnerability to sepsis. Few miR were modified in a similar manner across age or sex; however, these few miR were generally associated with neuroprotection against inflammation. In contrast, older males exhibit increased expression of several miRs linked to neurodegeneration, increased neuroinflammation, and cognitive impairment. The differences may contribute to age and sexually dimorphic responses to sepsis, and emphasize a need for precision/personalized therapeutics to address post-septic cognitive decline. miRs isolated from blood can provide diagnostic and prognostic information concerning sepsis [102, 103] and cognition $[26,28]$. Furthermore, systemic delivery of miR may protect against sepsis induced brain injury [104]. Thus, it may be important for future studies to examine the relationship between miRs detected in blood and brain.

\section{AUTHOR CONTRIBUTIONS}

AR performed experiments, analyzed data, wrote manuscript, and prepared illustrations and tables. TCF designed the experiments, analyzed data, wrote the manuscript, and constructed illustrations and tables. $\mathrm{AK}$, collected tissues and prepared illustrations, and edited the manuscript. PAE and LLM designed and edited the manuscript. JB performed experiments. JS, $\mathrm{DN}$, and HM performed surgery, animal care, and tissue collection.

\section{CONFLICTS OF INTEREST}

The authors declare no conflicts of interest related to this study.

\section{FUNDING}

Financial support by National Institutes of Aging Grant R01AG052258, R01AG037984, P30AG028740, R21AG068205, R01GM113945, P50GM111152, and T32 GM-008721 in burns, trauma, and perioperative injury by National Institute of General Medical Sciences, and the Evelyn F. McKnight Brain Research Foundation is highly appreciated.

\section{REFERENCES}

1. Horiguchi $H$, Loftus TJ, Hawkins RB, Raymond SL, Stortz JA, Hollen MK, Weiss BP, Miller ES, Bihorac A, Larson SD, Mohr AM, Brakenridge SC, Tsujimoto $\mathrm{H}$, et al, and Sepsis and Critical IIIness Research Center Investigators. Innate Immunity in the Persistent Inflammation, Immunosuppression, and Catabolism Syndrome and Its Implications for Therapy. Front Immunol. 2018; 9:595.

https://doi.org/10.3389/fimmu.2018.00595 PMID:29670613

2. Mankowski RT, Anton SD, Ghita GL, Brumback B, Cox MC, Mohr AM, Leeuwenburgh C, Moldawer LL, Efron PA, Brakenridge SC, Moore FA. Older Sepsis Survivors Suffer Persistent Disability Burden and Poor LongTerm Survival. J Am Geriatr Soc. 2020; 68:1962-9. https://doi.org/10.1111/igs.16435 PMID:32294254

3. Kumar S, Mankowski RT, Anton SD, Babu Balagopal P. Novel insights on the role of spexin as a biomarker of 
obesity and related cardiometabolic disease. Int J Obes (Lond). 2021; 45:2169-78.

https://doi.org/10.1038/s41366-021-00906-2 PMID:34253845

4. Singer M, Deutschman CS, Seymour CW, Shankar-Hari M, Annane D, Bauer M, Bellomo R, Bernard GR, Chiche JD, Coopersmith CM, Hotchkiss RS, Levy MM, Marshall JC, et al. The Third International Consensus Definitions for Sepsis and Septic Shock (Sepsis-3). JAMA. 2016; 315:801-10.

https://doi.org/10.1001/jama.2016.0287 PMID:26903338

5. Nacionales DC, Gentile LF, Vanzant E, Lopez MC, Cuenca A, Cuenca AG, Ungaro R, Li Y, Baslanti TO, Bihorac A, Moore FA, Baker HV, Leeuwenburgh C, et al. Aged mice are unable to mount an effective myeloid response to sepsis. J Immunol. 2014; 192:612-22.

https://doi.org/10.4049/jimmunol.1302109 PMID:24337739

6. Gracner T, Agarwal M, Murali KP, Stone PW, Larson EL, Furuya EY, Harrison JM, Dick AW. Association of Infection-Related Hospitalization With Cognitive Impairment Among Nursing Home Residents. JAMA Netw Open. 2021; 4:e217528.

https://doi.org/10.1001/jamanetworkopen.2021.7528 PMID:33890988

7. Gao Q, Hernandes MS. Sepsis-Associated Encephalopathy and Blood-Brain Barrier Dysfunction. Inflammation. 2021; 44:2143-50. https://doi.org/10.1007/s10753-021-01501-3 PMID:34291398

8. Kumar G, Kumar N, Taneja A, Kaleekal T, Tarima S, McGinley E, Jimenez E, Mohan A, Khan RA, Whittle $J$, Jacobs E, Nanchal R, and Milwaukee Initiative in Critical Care Outcomes Research (MICCOR) Group of Investigators. Nationwide trends of severe sepsis in the 21st century (2000-2007). Chest. 2011; 140:1223-31.

https://doi.org/10.1378/chest.11-0352

PMID:21852297

9. Turnbull IR, Clark AT, Stromberg PE, Dixon DJ, Woolsey CA, Davis CG, Hotchkiss RS, Buchman TG, Coopersmith CM. Effects of aging on the immunopathologic response to sepsis. Crit Care Med. 2009; 37:1018-23.

https://doi.org/10.1097/CCM.0b013e3181968f3a PMID:19237912

10. Chung HY, Wickel J, Brunkhorst FM, Geis C. SepsisAssociated Encephalopathy: From Delirium to Dementia? J Clin Med. 2020; 9:703.

https://doi.org/10.3390/jcm9030703

PMID: $\underline{32150970}$
11. Bouza C, Martínez-Alés G, López-Cuadrado T. The impact of dementia on hospital outcomes for elderly patients with sepsis: A population-based study. PLoS One. 2019; 14:e0212196.

https://doi.org/10.1371/journal.pone.0212196 PMID: $\underline{30779777}$

12. Vasek MJ, Garber C, Dorsey D, Durrant DM, Bollman B, Soung A, Yu J, Perez-Torres C, Frouin A, Wilton DK, Funk K, DeMasters BK, Jiang $X$, et al. A complementmicroglial axis drives synapse loss during virus-induced memory impairment. Nature. 2016; 534:538-43.

https://doi.org/10.1038/nature18283

PMID:27337340

13. Barter J, Kumar A, Rani A, Colon-Perez LM, Febo M, Foster TC. Differential Effect of Repeated Lipopolysaccharide Treatment and Aging on Hippocampal Function and Biomarkers of Hippocampal Senescence. Mol Neurobiol. 2020; 57:4045-59.

https://doi.org/10.1007/s12035-020-02008-y

PMID:32651758

14. Barter J, Kumar A, Bean L, Ciesla M, Foster TC. Adulthood systemic inflammation accelerates the trajectory of age-related cognitive decline. Aging (Albany NY). 2021; 13:22092-108.

https://doi.org/10.18632/aging.203588

PMID: $\underline{34587117}$

15. Barter J, Kumar A, Stortz JA, Hollen M, Nacionales D, Efron PA, Moldawer LL, Foster TC. Age and Sex Influence the Hippocampal Response and Recovery Following Sepsis. Mol Neurobiol. 2019; 56:8557-72.

https://doi.org/10.1007/s12035-019-01681-y PMID:31278440

16. Spolarics Z, Peña G, Qin Y, Donnelly RJ, Livingston DH. Inherent X-Linked Genetic Variability and Cellular Mosaicism Unique to Females Contribute to SexRelated Differences in the Innate Immune Response. Front Immunol. 2017; 8:1455.

https://doi.org/10.3389/fimmu.2017.01455 PMID:29180997

17. Vázquez-Martínez ER, García-Gómez E, CamachoArroyo I, González-Pedrajo B. Sexual dimorphism in bacterial infections. Biol Sex Differ. 2018; 9:27. https://doi.org/10.1186/s13293-018-0187-5 PMID:29925409

18. Mangold CA, Masser DR, Stanford DR, Bixler GV, Pisupati A, Giles CB, Wren JD, Ford MM, Sonntag WE, Freeman WM. CNS-wide Sexually Dimorphic Induction of the Major Histocompatibility Complex 1 Pathway With Aging. J Gerontol A Biol Sci Med Sci. 2017; 72:16-29.

https://doi.org/10.1093/gerona/glv232

PMID:26786204 
19. Masser DR, Hadad N, Porter HL, Mangold CA, Unnikrishnan A, Ford MM, Giles CB, Georgescu C, Dozmorov MG, Wren JD, Richardson A, Stanford DR, Freeman WM. Sexually divergent DNA methylation patterns with hippocampal aging. Aging Cell. 2017; 16:1342-52.

https://doi.org/10.1111/acel.12681

PMID:28948711

20. Bie B, Wu J, Yang H, Xu JJ, Brown DL, Naguib M. Epigenetic suppression of neuroligin 1 underlies amyloid-induced memory deficiency. Nat Neurosci. 2014; 17:223-31.

https://doi.org/10.1038/nn.3618

PMID:24441681

21. Matt SM, Lawson MA, Johnson RW. Aging and peripheral lipopolysaccharide can modulate epigenetic regulators and decrease IL-1 $\beta$ promoter DNA methylation in microglia. Neurobiol Aging. 2016; 47:1-9.

https://doi.org/10.1016/j.neurobiolaging.2016.07.006 PMID:27500965

22. Matt SM, Zimmerman JD, Lawson MA, Bustamante AC, Uddin M, Johnson RW. Inhibition of DNA Methylation With Zebularine Alters Lipopolysaccharide-Induced Sickness Behavior and Neuroinflammation in Mice. Front Neurosci. 2018; 12:636.

https://doi.org/10.3389/fnins.2018.00636 PMID: $\underline{30279646}$

23. Nicolia V, Cavallaro RA, López-González I, Maccarrone M, Scarpa S, Ferrer I, Fuso A. DNA Methylation Profiles of Selected Pro-Inflammatory Cytokines in Alzheimer Disease. J Neuropathol Exp Neurol. 2017; 76:27-31.

https://doi.org/10.1093/inen/nlw099

PMID:28053004

24. Shepherd R, Cheung AS, Pang K, Saffery R, Novakovic B. Sexual Dimorphism in Innate Immunity: The Role of Sex Hormones and Epigenetics. Front Immunol. 2021; 11:604000.

https://doi.org/10.3389/fimmu.2020.604000 PMID:33584674

25. Barter JD, Foster TC. Aging in the Brain: New Roles of Epigenetics in Cognitive Decline. Neuroscientist. 2018; 24:516-25.

https://doi.org/10.1177/1073858418780971

PMID:29877135

26. Gullett JM, Chen Z, O'Shea A, Akbar M, Bian J, Rani A, Porges EC, Foster TC, Woods AJ, Modave F, Cohen RA. MicroRNA predicts cognitive performance in healthy older adults. Neurobiol Aging. 2020; 95:186-94. https://doi.org/10.1016/j.neurobiolaging.2020.07.023 PMID: $\underline{32846274}$
27. He M, Zhang HN, Tang ZC, Gao SG. Diagnostic and Therapeutic Potential of Exosomal MicroRNAs for Neurodegenerative Diseases. Neural Plast. 2021; 2021:8884642.

https://doi.org/10.1155/2021/8884642

PMID:34054944

28. Rani A, O'Shea A, lanov L, Cohen RA, Woods AJ, Foster TC. miRNA in Circulating Microvesicles as Biomarkers for Age-Related Cognitive Decline. Front Aging Neurosci. 2017; 9:323.

https://doi.org/10.3389/fnagi.2017.00323

PMID:29046635

29. Zia A, Farkhondeh T, Sahebdel F, Pourbagher-Shahri AM, Samarghandian S. Key miRNAs in Modulating Aging and Longevity: A Focus on Signaling Pathways and Cellular Targets. Curr Mol Pharmacol. 2021. [Epub ahead of print].

https://doi.org/10.2174/1874467214666210917141541 PMID:34533452

30. Olivieri F, Procopio AD, Montgomery RR. Effect of aging on microRNAs and regulation of pathogen recognition receptors. Curr Opin Immunol. 2014; 29:29-37.

https://doi.org/10.1016/j.coi.2014.03.006 PMID:24769423

31. Kim T, Chelluboina B, Chokkalla AK, Vemuganti R. Age and sex differences in the pathophysiology of acute CNS injury. Neurochem Int. 2019; 127:22-8. https://doi.org/10.1016/i.neuint.2019.01.012 PMID: 30654116

32. National Research Council (US) Committee for the Update of the Guide for the Care and Use of Laboratory Animals. Guide for the Care and Use of Laboratory Animals. 8th ed. Washington (DC): National Academies Press (US). 2011.

https://doi.org/10.17226/12910

PMID:21595115

33. Franklin CL, Ericsson AC. Microbiota and reproducibility of rodent models. Lab Anim (NY). 2017; 46:114-22. https://doi.org/10.1038/laban.1222 PMID:28328896

34. Stortz JA, Hollen MK, Nacionales DC, Horiguchi $H$, Ungaro R, Dirain ML, Wang Z, Wu Q, Wu KK, Kumar A, Foster TC, Stewart BD, Ross JA, et al. Old Mice Demonstrate Organ Dysfunction as well as Prolonged Inflammation, Immunosuppression, and Weight Loss in a Modified Surgical Sepsis Model. Crit Care Med. 2019; 47:e919-29. https://doi.org/10.1097/CCM.0000000000003926 PMID: $\underline{31389840}$

35. Efron PA, Darden DB, Wang Z, Nacionales DC, Lopez MC, Hawkins RB, Cox MC, Rincon JC, Ungaro R, Dirain 
ML, Ghita GL, Chen T, Billiar TR, et al. Transcriptomic responses from improved murine sepsis models can better mimic human surgical sepsis. FASEB J. 2021; 35:e21156.

https://doi.org/10.1096/fj.202002150R

PMID: $\underline{3140449}$

36. Ianov L, De Both M, Chawla MK, Rani A, Kennedy AJ, Piras I, Day JJ, Siniard A, Kumar A, Sweatt JD, Barnes CA, Huentelman MJ, Foster TC. Hippocampal Transcriptomic Profiles: Subfield Vulnerability to Age and Cognitive Impairment. Front Aging Neurosci. 2017; 9:383.

https://doi.org/10.3389/fnagi.2017.00383

PMID:29276487

37. Ianov L, Rani A, Beas BS, Kumar A, Foster TC. Transcription Profile of Aging and Cognition-Related Genes in the Medial Prefrontal Cortex. Front Aging Neurosci. 2016; 8:113.

https://doi.org/10.3389/fnagi.2016.00113 PMID:27242522

38. Blalock EM, Chen KC, Sharrow K, Herman JP, Porter NM, Foster TC, Landfield PW. Gene microarrays in hippocampal aging: statistical profiling identifies novel processes correlated with cognitive impairment. J Neurosci. 2003; 23:3807-19. https://doi.org/10.1523/JNEUROSCl.23-09$\underline{03807.2003}$ PMID:12736351

39. Aenlle KK, Foster TC. Aging alters the expression of genes for neuroprotection and synaptic function following acute estradiol treatment. Hippocampus. 2010; 20:1047-60.

https://doi.org/10.1002/hipo.20703 PMID:19790252

40. Wang J, Wang X, Wang L, Sun C, Xie C, Li Z. MiR-let$7 \mathrm{~d}-3 p$ regulates $\mathrm{IL}-17$ expression through targeting AKT1/mTOR signaling in CD4 ${ }^{+} \mathrm{T}$ cells. In Vitro Cell Dev Biol Anim. 2020; 56:67-74.

https://doi.org/10.1007/s11626-019-00409-5 PMID:31768762

41. Wu W, Duan C, Lv H, Song J, Cai W, Fu K, Xu J. MiRlet-7d-3p inhibits granulosa cell proliferation by targeting TLR4 in polycystic ovary syndrome. Reprod Toxicol. 2021; 106:61-8.

https://doi.org/10.1016/i.reprotox.2021.10.003 PMID:34655744

42. Wang S, Guo C, Yu M, Ning X, Yan B, Zhao J, Yang A, Yan $\mathrm{H}$. Identification of $\mathrm{H}_{2} \mathrm{O}_{2}$ induced oxidative stress associated microRNAs in HLE-B3 cells and their clinical relevance to the progression of age-related nuclear cataract. BMC Ophthalmol. 2018; 18:93. https://doi.org/10.1186/s12886-018-0766-6 PMID:29653565
43. Wu F, Han B, Wu S, Yang L, Leng S, Li M, Liao J, Wang $G$, Ye $Q$, Zhang $Y$, Chen $H$, Chen $X$, Zhong $M$, et al. Circular RNA TLK1 Aggravates Neuronal Injury and Neurological Deficits after Ischemic Stroke via miR335-3p/TIPARP. J Neurosci. 2019; 39:7369-93. https://doi.org/10.1523/JNEUROSCI.0299-19.2019 PMID:31311824

44. Oliveira SR, Dionísio PA, Correia Guedes L, Gonçalves $\mathrm{N}$, Coelho M, Rosa MM, Amaral JD, Ferreira JJ, Rodrigues CMP. Circulating Inflammatory miRNAs Associated with Parkinson's Disease Pathophysiology. Biomolecules. 2020; 10:945.

https://doi.org/10.3390/biom10060945

PMID: $\underline{32585840}$

45. Raihan O, Brishti A, Molla MR, Li W, Zhang $Q$, Xu P, Khan MI, Zhang J, Liu Q. The Age-dependent Elevation of miR-335-3p Leads to Reduced Cholesterol and Impaired Memory in Brain. Neuroscience. 2018; 390:160-73.

https://doi.org/10.1016/j.neuroscience.2018.08.003 PMID:30125687

46. Martin EC, Conger AK, Yan TJ, Hoang VT, Miller DF, Buechlein A, Rusch DB, Nephew KP, Collins-Burow BM, Burow ME. MicroRNA-335-5p and $-3 p$ synergize to inhibit estrogen receptor alpha expression and promote tamoxifen resistance. FEBS Lett. 2017; 591:382-92.

https://doi.org/10.1002/1873-3468.12538

PMID:28008602

47. Morquette B, Juźwik CA, Drake SS, Charabati M, Zhang Y, Lécuyer MA, Galloway DA, Dumas A, de Faria Junior O, Paradis-Isler N, Bueno M, Rambaldi I, Zandee $S$, et al. MicroRNA-223 protects neurons from degeneration in experimental autoimmune encephalomyelitis. Brain. 2019; 142:2979-95.

https://doi.org/10.1093/brain/awz245 PMID:31412103

48. Xu W, Zhang L, Geng Y, Liu Y, Zhang N. Long noncoding RNA GAS5 promotes microglial inflammatory response in Parkinson's disease by regulating NLRP3 pathway through sponging miR223-3p. Int Immunopharmacol. 2020; 85:106614. https://doi.org/10.1016/i.intimp.2020.106614 PMID:32470877

49. Zhao Y, Gan Y, Xu G, Hua K, Liu D. Exosomes from MSCs overexpressing microRNA-223-3p attenuate cerebral ischemia through inhibiting microglial M1 polarization mediated inflammation. Life Sci. 2020; 260:118403.

https://doi.org/10.1016/j.Ifs.2020.118403 PMID: $\underline{32926923}$

50. Fang $R$, Zhao NN, Zeng $K X$, Wen $Q$, Xiao $P$, Luo $X$, Liu $\mathrm{XW}$, Wang YL. MicroRNA-544 inhibits inflammatory 
response and cell apoptosis after cerebral ischemia reperfusion by targeting IRAK4. Eur Rev Med Pharmacol Sci. 2018; 22:5605-13.

https://doi.org/10.26355/eurrev 20180915825 PMID:30229835

51. Lu MY, Wu JR, Liang RB, Wang YP, Zhu YC, Ma ZT, Zhang H, Zan J, Tan W. Upregulation of miR-219a-5p Decreases Cerebral Ischemia/Reperfusion Injury In Vitro by Targeting Pde4d. J Stroke Cerebrovasc Dis. 2020; 29:104801.

https://doi.org/10.1016/i.jstrokecerebrovasdis.2020. 104801

PMID:32249206

52. Osorio-Querejeta I, Carregal-Romero S, AyerdiIzquierdo A, Mäger I, A NL, Wood M, Egimendia A, Betanzos M, Alberro A, Iparraguirre L, Moles L, Llarena I, Möller M, et al. MiR-219a-5p Enriched Extracellular Vesicles Induce OPC Differentiation and EAE Improvement More Efficiently Than Liposomes and Polymeric Nanoparticles. Pharmaceutics. 2020; 12:186.

https://doi.org/10.3390/pharmaceutics12020186 PMID: $\underline{32098213}$

53. Li N, Pan J, Liu W, Li Y, Li F, Liu M. MicroRNA-15a-5p serves as a potential biomarker and regulates the viability and apoptosis of hippocampus neuron in children with temporal lobe epilepsy. Diagn Pathol. 2020; 15:46.

https://doi.org/10.1186/s13000-020-00944-w PMID:32384924

54. Liu X, Geng J, Guo H, Zhao H, Ai Y. Propofol inhibited apoptosis of hippocampal neurons in status epilepticus through miR-15a-5p/NR2B/ERK1/2 pathway. Cell Cycle. 2020; 19:1000-11. https://doi.org/10.1080/15384101.2020.1743909 PMID: $\underline{2212891}$

55. Liu Q, Hou A, Zhang Y, Guo Y, Li J, Yao Y, Niu K, Li H, Ma Y, Cao J. MiR-190a potentially ameliorates postoperative cognitive dysfunction by regulating Tiam1. BMC Genomics. 2019; 20:670. https://doi.org/10.1186/s12864-019-6035-0 PMID:31438846

56. Liu $\mathrm{Q}$, He $\mathrm{H}$, Zeng $\mathrm{T}$, Huang $\mathrm{Z}$, Fan $\mathrm{T}, \mathrm{Wu} \mathrm{Q}$. Neural-specific expression of miR-344-3p during mouse embryonic development. J Mol Histol. 2014; 45:363-72.

https://doi.org/10.1007/s10735-013-9555-y PMID:24292630

57. Lv J, Zeng Y, Qian Y, Dong J, Zhang Z, Zhang J. MicroRNA let-7c-5p improves neurological outcomes in a murine model of traumatic brain injury by suppressing neuroinflammation and regulating microglial activation. Brain Res. 2018; 1685:91-104. https://doi.org/10.1016/j.brainres.2018.01.032 PMID:29408500

58. Chi NF, Chiou HY, Chou SY, Hu CJ, Chen KY, Chang CF, Hsieh YC. Hyperglycemia-related FAS gene and hsalet-7b-5p as markers of poor outcomes for ischaemic stroke. Eur J Neurol. 2020; 27:1647-55.

https://doi.org/10.1111/ene.14288

PMID: $\underline{32352616}$

59. Ponnusamy V, Ip RTH, Mohamed MAE, Clarke P, Wozniak E, Mein C, Schwendimann L, Barlas A, Chisholm P, Chakkarapani E, Michael-Titus AT, Gressens P, Yip PK, Shah DK. Neuronal let-7b-5p acts through the Hippo-YAP pathway in neonatal encephalopathy. Commun Biol. 2021; 4:1143. https://doi.org/10.1038/s42003-021-02672-3 PMID: $\underline{34593980}$

60. Vinciguerra A, Cepparulo P, Anzilotti S, Cuomo O, Valsecchi V, Amoroso S, Annunziato L, Pignataro G. Remote postconditioning ameliorates stroke damage by preventing let-7a and miR-143 up-regulation. Theranostics. 2020; 10:12174-88. https://doi.org/10.7150/thno.48135 PMID:33204336

61. Guan C, Wang Y. LncRNA CASC9 attenuates lactate dehydrogenase-mediated oxidative stress and inflammation in spinal cord injury via sponging miR383-5p. Inflammation. 2021; 44:923-33. https://doi.org/10.1007/s10753-020-01387-7 PMID:33438067

62. Jiang C, Dong N, Feng J, Hao M. MiRNA-190 exerts neuroprotective effects against ischemic stroke through Rho/Rho-kinase pathway. Pflugers Arch. 2021; 473:121-30.

https://doi.org/10.1007/s00424-020-02490-2

PMID:33196911

63. Sun $Q$, Wang $S$, Chen J, Cai $H$, Huang $W$, Zhang $Y$, Wang L, Xing Y. MicroRNA-190 alleviates neuronal damage and inhibits neuroinflammation via NIrp3 in MPTP-induced Parkinson's disease mouse model. J Cell Physiol. 2019; 234:23379-87. https://doi.org/10.1002/jcp.28907 PMID:31232472

64. Murphy AJ, Guyre PM, Pioli PA. Estradiol suppresses NF-kappa $B$ activation through coordinated regulation of let-7a and miR-125b in primary human macrophages. J Immunol. 2010; 184:5029-37. https://doi.org/10.4049/jimmunol.0903463 PMID:20351193

65. Azotla-Vilchis CN, Sanchez-Celis D, Agonizantes-Juárez LE, Suárez-Sánchez R, Hernández-Hernández JM, Peña J, Vázquez-Santillán K, Leyva-García N, Ortega A, Maldonado V, Rangel C, Magaña JJ, Cisneros B, Hernández-Hernández $O$. Transcriptome Analysis 
Reveals Altered Inflammatory Pathway in an Inducible Glial Cell Model of Myotonic Dystrophy Type 1. Biomolecules. 2021; 11:159.

https://doi.org/10.3390/biom11020159

PMID:33530452

66. Ortega FJ, Moreno M, Mercader JM, MorenoNavarrete JM, Fuentes-Batllevell N, Sabater M, Ricart W, Fernández-Real JM. Inflammation triggers specific microRNA profiles in human adipocytes and macrophages and in their supernatants. Clin Epigenetics. 2015; 7:49.

https://doi.org/10.1186/s13148-015-0083-3

PMID:25926893

67. Xu J, Feng Y, Jeyaram A, Jay SM, Zou L, Chao W. Circulating Plasma Extracellular Vesicles from Septic Mice Induce Inflammation via MicroRNA- and TLR7Dependent Mechanisms. J Immunol. 2018; 201:3392400.

https://doi.org/10.4049/jimmunol.1801008 PMID:30355788

68. Zhang Y, Yang J, Zhou X, Wang N, Li Z, Zhou Y, Feng J, Shen $D$, Zhao $W$. Knockdown of miR-222 inhibits inflammation and the apoptosis of LPS-stimulated human intervertebral disc nucleus pulposus cells. Int J Mol Med. 2019; 44:1357-65.

https://doi.org/10.3892/ijmm.2019.4314 PMID:31432092

69. Quero L, Tiaden AN, Hanser E, Roux J, Laski A, Hall J, Kyburz D. miR-221-3p Drives the Shift of M2Macrophages to a Pro-Inflammatory Function by Suppressing JAK3/STAT3 Activation. Front Immunol. 2020; 10:3087.

https://doi.org/10.3389/fimmu.2019.03087 PMID:32047494

70. Sticht C, De La Torre C, Parveen A, Gretz N. miRWalk: An online resource for prediction of microRNA binding sites. PLoS One. 2018; 13:e0206239. https://doi.org/10.1371/journal.pone.0206239 PMID:30335862

71. Hill CG, Matyunina LV, Walker D, Benigno BB, McDonald JF. Transcriptional override: a regulatory network model of indirect responses to modulations in microRNA expression. BMC Syst Biol. 2014; 8:36.

https://doi.org/10.1186/1752-0509-8-36 PMID:24666724

72. Shahab SW, Matyunina LV, Mezencev R, Walker LD, Bowen NJ, Benigno BB, McDonald JF. Evidence for the complexity of microRNA-mediated regulation in ovarian cancer: a systems approach. PLoS One. 2011; 6:e22508.

https://doi.org/10.1371/journal.pone.0022508 PMID:21811625
73. McQuail JA, Dunn AR, Stern $Y$, Barnes CA, Kempermann G, Rapp PR, Kaczorowski CC, Foster TC. Cognitive Reserve in Model Systems for Mechanistic Discovery: The Importance of Longitudinal Studies. Front Aging Neurosci. 2021; 12:607685.

https://doi.org/10.3389/fnagi.2020.607685 PMID:33551788

74. Kaidonis G, Rao AN, Ouyang YB, Stary CM. Elucidating sex differences in response to cerebral ischemia: immunoregulatory mechanisms and the role of microRNAs. Prog Neurobiol. 2019; 176:73-85.

https://doi.org/10.1016/i.pneurobio.2018.08.001 PMID:30121237

75. Markle JG, Fish EN. SeXX matters in immunity. Trends Immunol. 2014; 35:97-104.

https://doi.org/10.1016/i.it.2013.10.006 PMID:24239225

76. Zuk M. The sicker sex. PLoS Pathog. 2009; 5:e1000267. https://doi.org/10.1371/journal.ppat.1000267 PMID:19180235

77. Bai YY, Niu JZ. miR-222 regulates brain injury and inflammation following intracerebral hemorrhage by targeting ITGB8. Mol Med Rep. 2020; 21:1145-53. https://doi.org/10.3892/mmr.2019.10903 PMID:31894320

78. Brown PN, Yin H. PNA-based microRNA inhibitors elicit anti-inflammatory effects in microglia cells. Chem Commun (Camb). 2013; 49:4415-7.

https://doi.org/10.1039/c2cc36540e

PMID:23111503

79. Feng J, Wang $M$, Li M, Yang J, Jia J, Liu L, Zhou J, Zhang C, Wang X. Serum miR-221-3p as a new potential biomarker for depressed mood in perioperative patients. Brain Res. 2019; 1720:146296. https://doi.org/10.1016/j.brainres.2019.06.015 PMID: $\underline{31211948}$

80. Shen $Y$, Lu H, Song G. MiR-221-3p and miR-92a-3p enhances smoking-induced inflammation in COPD. J Clin Lab Anal. 2021; 35:e23857.

https://doi.org/10.1002/jcla.23857 PMID:34097306

81. Morgan CP, Bale TL. Sex differences in microRNAmRNA networks: examination of novel epigenetic programming mechanisms in the sexually dimorphic neonatal hypothalamus. Biol Sex Differ. 2017; 8:27.

https://doi.org/10.1186/s13293-017-0149-3 PMID:28810930

82. Liu B, Che Q, Qiu H, Bao W, Chen X, Lu W, Li B, Wan X. Elevated MiR-222-3p promotes proliferation and invasion of endometrial carcinoma via targeting ER $\alpha$. PLoS One. 2014; 9:e87563. 
https://doi.org/10.1371/journal.pone.0087563 PMID:24498137

83. Liu D, Liang Y, Chen M, Yang F, Yao S. Knockdown of circ_0075503 suppresses cell migration and invasion by regulating miR-15a-5p and KLF12 in endometriosis. Mol Cell Biochem. 2021; 476:3845-56. https://doi.org/10.1007/s11010-021-04202-5 PMID:34117589

84. Ahmad N, Kushwaha P, Karvande A, Tripathi AK, Kothari P, Adhikary S, Khedgikar V, Mishra VK, Trivedi R. MicroRNA-672-5p Identified during Weaning Reverses Osteopenia and Sarcopenia in Ovariectomized Mice. Mol Ther Nucleic Acids. 2019; 14:536-49.

https://doi.org/10.1016/i.omtn.2019.01.002 PMID:30769134

85. Endo $\mathrm{Y}$, Toyama T, Takahashi S, Yoshimoto N, Iwasa M, Asano T, Fujii Y, Yamashita H. miR-1290 and its potential targets are associated with characteristics of estrogen receptor $\alpha$-positive breast cancer. Endocr Relat Cancer. 2013; 20:91-102. https://doi.org/10.1530/ERC-12-0207 PMID:23183268

86. Herichova I, Reis R, Hasakova K, Vician M. Downregulation of miR-30c-5p expression in colorectal cancer tissue is sex-dependent. Physiol Res. 2020 (Suppl 3); 69:\$479-87.

https://doi.org/10.33549/physiolres.934598 PMID: $\underline{3476170}$

87. Pan Q, Guo K, Xue M, Tu Q. Estradiol exerts a neuroprotective effect on SH-SY5Y cells through the miR-106b-5p/TXNIP axis. J Biochem Mol Toxicol. 2021; 35:e22861. https://doi.org/10.1002/jbt.22861 PMID: $\underline{34318539}$

88. Vidal-Gómez $X$, Pérez-Cremades $D$, Mompeón A, Dantas AP, Novella S, Hermenegildo C. MicroRNA as Crucial Regulators of Gene Expression in EstradiolTreated Human Endothelial Cells. Cell Physiol Biochem. 2018; 45:1878-92. https://doi.org/10.1159/000487910 PMID:29510375

89. Na HST, Nuo M, Meng QT, Xia ZY. The Pathway of Let7a-1/2-3p and HMGB1 Mediated Dexmedetomidine Inhibiting Microglia Activation in Spinal Cord Ischemia-Reperfusion Injury Mice. J Mol Neurosci. 2019; 69:106-14. https://doi.org/10.1007/s12031-019-01338-4 PMID: $\underline{31190218}$

90. Le L, Niu L, Barter MJ, Young DA, Dalmay T, Clark IM, Swingler TE. The role of microRNA-3085 in chondrocyte function. Sci Rep. 2020; 10:21923. https://doi.org/10.1038/s41598-020-78606-6 PMID:33318505

91. Cai Z, Zheng F, Ding Y, Zhan Y, Gong R, Li J, Aschner M, Zhang Q, Wu S, Li H. Nrf2-regulated miR-380-3p blocks the translation of Sp3 protein and its mediation of paraquat-induced toxicity in mouse neuroblastoma N2a cells. Toxicol Sci. 2019; 171:515-29. https://doi.org/10.1093/toxsci/kfz162 PMID:31368498

92. Li X, Lou X, Xu S, Du J, Wu J. Hypoxia inducible factor1 (HIF-1 $\alpha$ ) reduced inflammation in spinal cord injury via miR-380-3p/ NLRP3 by Circ 0001723. Biol Res. 2020; 53:35.

https://doi.org/10.1186/s40659-020-00302-6 PMID: $\underline{32819442}$

93. Jiang $M$, Yun $Q$, Shi $F$, Niu G, Gao $Y$, Xie $S$, Yu $S$. Downregulation of miR-384-5p attenuates rotenoneinduced neurotoxicity in dopaminergic SH-SY5Y cells through inhibiting endoplasmic reticulum stress. Am J Physiol Cell Physiol. 2016; 310:C755-63. https://doi.org/10.1152/ajpcell.00226.2015 PMID:26864693

94. Wang Z, Du X, Yang Y, Zhang G. Study on miR-384$5 p$ activates TGF- $\beta$ signaling pathway to promote neuronal damage in abutment nucleus of rats based on deep learning. Artif Intell Med. 2019; 101:101740.

https://doi.org/10.1016/j.artmed.2019.101740 PMID:31813493

95. Sun C, Jia N, Li R, Zhang Z, Zhong Y, Han K. miR-143-3p inhibition promotes neuronal survival in an Alzheimer's disease cell model by targeting neuregulin-1. Folia Neuropathol. 2020; 58:10-21. https://doi.org/10.5114/fn.2020.94002 PMID: $\underline{32337953}$

96. Yu $Y$, Zhang $W$, Zhu $D$, Wang $H$, Shao $H$, Zhang $Y$. LncRNA Rian ameliorates sevoflurane anesthesiainduced cognitive dysfunction through regulation of miR-143-3p/LIMK1 axis. Hum Cell. 2021; 34:808-18. https://doi.org/10.1007/s13577-021-00502-6 PMID:33616869

97. Wang $\mathrm{HE}$, Kabeto MM, Gray M, Wadley VG, Muntner P, Judd SE, Safford MM, Kempker J, Levine DA. Trajectory of Cognitive Decline After Sepsis. Crit Care Med. 2021; 49:1083-94. https://doi.org/10.1097/CCM.0000000000004897 PMID:33666392

98. Schaafsma $\mathrm{W}$, Zhang $\mathrm{X}$, van Zomeren $\mathrm{KC}$, Jacobs $\mathrm{S}$, Georgieva PB, Wolf SA, Kettenmann $\mathrm{H}$, Janova $\mathrm{H}$, Saiepour N, Hanisch UK, Meerlo P, van den Elsen PJ, Brouwer $\mathrm{N}$, et al. Long-lasting pro-inflammatory suppression of microglia by LPS-preconditioning is 
mediated by RelB-dependent epigenetic silencing. Brain Behav Immun. 2015; 48:205-21.

https://doi.org/10.1016/j.bbi.2015.03.013

PMID:25843371

99. Wendeln AC, Degenhardt K, Kaurani L, Gertig M, Ulas T, Jain G, Wagner J, Häsler LM, Wild K, Skodras A, Blank T, Staszewski O, Datta $M$, et al. Innate immune memory in the brain shapes neurological disease hallmarks. Nature. 2018; 556:332-8. https://doi.org/10.1038/s41586-018-0023-4 PMID:29643512

100. Yegla B, Foster TC. Operationally defining cognitive reserve genes. Neurobiol Aging. 2022; 110:96-105. https://doi.org/10.1016/j.neurobiolaging.2021.08.015 PMID:34565615

101. Sinha P, Rani A, Kumar A, Riva A, Brant JO, Foster TC. Examination of CA1 Hippocampal DNA Methylation as a Mechanism for Closing of Estrogen's Critical Window. Front Aging Neurosci. 2021; 13:717032. https://doi.org/10.3389/fnagi.2021.717032 PMID:34421577

102. Osca-Verdegal R, Beltrán-García J, Pallardó FV, García-Giménez JL. Role of microRNAs As Biomarkers in Sepsis-Associated Encephalopathy. Mol Neurobiol. 2021; 58:4682-93. https://doi.org/10.1007/s12035-021-02445-3 PMID:34160774

103. Huang J, Sun Z, Yan W, Zhu Y, Lin Y, Chen J, Shen B, Wang J. Identification of microRNA as sepsis biomarker based on miRNAs regulatory network analysis. Biomed Res Int. 2014; 2014:594350.

https://doi.org/10.1155/2014/594350 PMID:24809055

104. Nong A, Li Q, Huang Z, Xu Y, He K, Jia Y, Cen Z, Liao L, Huang Y. MicroRNA miR-126 attenuates brain injury in septic rats via NF-kB signaling pathway. Bioengineered. 2021; 12:2639-48.

https://doi.org/10.1080/21655979.2021.1937905 PMID:34115555

105. Li P, Shen M, Gao F, Wu J, Zhang J, Teng F, Zhang C. An Antagomir to MicroRNA-106b-5p Ameliorates Cerebral Ischemia and Reperfusion Injury in Rats Via Inhibiting Apoptosis and Oxidative Stress. Mol Neurobiol. 2017; 54:2901-21. https://doi.org/10.1007/s12035-016-9842-1 PMID: 27023223

106. Quan X, Liang H, Chen Y, Qin Q, Wei Y, Liang Z. Related Network and Differential Expression Analyses Identify Nuclear Genes and Pathways in the Hippocampus of Alzheimer Disease. Med Sci Monit. 2020; 26:e919311. https://doi.org/10.12659/MSM.919311 PMID:31989994
107. Sağır F, Ersoy Tunalı N, Tombul T, Koral G, Çırak S, Yılmaz V, Türkoğlu R, Tüzün E. miR-132-3p, miR106b-5p, and miR-19b-3p Are Associated with BrainDerived Neurotrophic Factor Production and Clinical Activity in Multiple Sclerosis: A Pilot Study. Genet Test Mol Biomarkers. 2021; 25:720-6. https://doi.org/10.1089/gtmb.2021.0183 PMID:34788141

108. Yu T, Fu H, Sun JJ, Ding DR, Wang H. miR-106b-5p upregulation is associated with microglial activation and inflammation in the mouse hippocampus following status epilepticus. Exp Brain Res. 2021; 239:3315-25. https://doi.org/10.1007/s00221-021-06208-3 PMID:34476536

109. De Santis G, Ferracin M, Biondani A, Caniatti L, Rosaria Tola M, Castellazzi M, Zagatti B, Battistini L, Borsellino G, Fainardi E, Gavioli R, Negrini M, Furlan $R$, Granieri E. Altered miRNA expression in $T$ regulatory cells in course of multiple sclerosis. J Neuroimmunol. 2010; 226:165-71.

https://doi.org/10.1016/i.jneuroim.2010.06.009 PMID:20637509

110. Yao B, Ye L, Chen J, Zhuo S, Lin H. LINC00473 protects against cerebral ischemia reperfusion injury via sponging miR-15b-5p and miR-15a-5p to regulate SRPK1 expression. Brain Inj. 2021; 35:1462-71. https://doi.org/10.1080/02699052.2021.1972156 PMID:34752173

111. de Queiroz KB, Dos Santos Fontes Pereira T, Araújo MSS, Gomez RS, Coimbra RS. Resveratrol Acts AntiInflammatory and Neuroprotective in an Infant Rat Model of Pneumococcal Meningitis by Modulating the Hippocampal miRNome. Mol Neurobiol. 2018; 55:8869-84.

https://doi.org/10.1007/s12035-018-1037-5 PMID:29611100

112. Luo $H$, Li Y, Liu B, Yang $Y, X u$ ZD. MicroRNA-15b-5p targets ERK1 to regulate proliferation and apoptosis in rat PC12 cells. Biomed Pharmacother. 2017; 92:1023-9.

https://doi.org/10.1016/i.biopha.2017.05.140 PMID:28609839

113. Zhu J, Xu X, Liang $Y$, Zhu R. Downregulation of microRNA-15b-5p Targeting the Akt3-Mediated GSK36/6-Catenin Signaling Pathway Inhibits Cell Apoptosis in Parkinson's Disease. Biomed Res Int. 2021; 2021:8814862.

https://doi.org/10.1155/2021/8814862 PMID:33506036

114. Liu T, Zhang $Y$, Liu W, Zhao J. LncRNA NEAT1 Regulates the Development of Parkinson's Disease by Targeting AXIN1 Via Sponging miR-212-3p. Neurochem Res. 2021; 46:230-40. 
https://doi.org/10.1007/s11064-020-03157-1 PMID:33241432

115. Wang $\mathrm{Y}$, Chang $\mathrm{Q}$. MicroRNA miR-212 regulates PDCD4 to attenuate $A \beta_{25-35}$-induced neurotoxicity via PI3K/AKT signaling pathway in Alzheimer's disease. Biotechnol Lett. 2020; 42:1789-97. https://doi.org/10.1007/s10529-020-02915-z PMID:32474742

116. Wu L, Du Q, Wu C. CircLPAR1/miR-212-3p/ZNF217 feedback loop promotes amyloid $\beta$-induced neuronal injury in Alzheimer's Disease. Brain Res. 2021; 1770:147622.

https://doi.org/10.1016/i.brainres.2021.147622 PMID: $\underline{34403662}$

117. Duan R, Wang SY, Wei B, Deng Y, Fu XX, Gong PY, E $Y$, Sun XJ, Cao HM, Shi JQ, Jiang T, Zhang YD. Angiotensin-(1-7) Analogue AVE0991 Modulates Astrocyte-Mediated Neuroinflammation via IncRNA SNHG14/miR-223-3p/NLRP3 Pathway and Offers Neuroprotection in a Transgenic Mouse Model of Alzheimer's Disease. J Inflamm Res. 2021; 14:7007-19. https://doi.org/10.2147/JIR.S343575 PMID: $\underline{34955647}$

118. Liao J, Liu J, Long G, Lv X. MiR-30b-5p attenuates neuropathic pain by the CYP24A1-Wnt/ $\beta$-catenin signaling in $\mathrm{CCl}$ rats. Exp Brain Res. 2021. [Epub ahead of print].

https://doi.org/10.1007/s00221-021-06253-y PMID:34748047

119. Sun B, Ou H, Ren F, Guan Y, Huan Y, Cai H. Propofol Protects against Cerebral Ischemia/Reperfusion Injury by Down-Regulating Long Noncoding RNA SNHG14. ACS Chem Neurosci. 2021; 12:3002-14. https://doi.org/10.1021/acschemneuro.1c00059 PMID:34369750

120. Yang $M$, Wang $X$, Fan $Y$, Chen $Y$, Sun $D, X u X$, Wang J, Gu G, Peng R, Shen T, Liu X, Li F, Wang $Y$, et al. Semaphorin 3A Contributes to Secondary BloodBrain Barrier Damage After Traumatic Brain Injury. Front Cell Neurosci. 2019; 13:117. https://doi.org/10.3389/fncel.2019.00117 PMID:

121. Yang B, Nie Y, Wang L, Xiong W. Flurbiprofen axetil protects against cerebral ischemia/reperfusion injury via regulating miR-30c-5p and SOX9. Chem Biol Drug Des. 2022; 99:197-205. https://doi.org/10.1111/cbdd.13973 PMID:34651418

122. Zhang $H$, Li M, Liang J, Li $M$, Sun X. Long Non-coding RNA PVT1 Inhibits miR-30c-5p to Upregulate Rock2 to Modulate Cerebral Ischemia/Reperfusion Injury
Through MAPK Signaling Pathway Activation. Mol Neurobiol. 2021; 58:6032-48.

https://doi.org/10.1007/s12035-021-02539-y PMID:34436749

123. Zhang L, Chen X, Chang M, Jiao B. MiR-30c-5p/ATG5 Axis Regulates the Progression of Parkinson's Disease. Front Cell Neurosci. 2021; 15:644507. https://doi.org/10.3389/fncel.2021.644507 PMID:34113238

124. Qian $H$, Shang $Q$, Liang $M$, Gao B, Xiao J, Wang J, Li A, Yang C, Yin J, Chen G, Li T, Liu X. MicroRNA-31$3 p /$ RhoA signaling in the dorsal hippocampus modulates methamphetamine-induced conditioned place preference in mice. Psychopharmacology (Berl). 2021; 238:3207-19. https://doi.org/10.1007/s00213-021-05936-2 PMID:34313802

125. Sheinerman KS, Tsivinsky VG, Abdullah L, Crawford F, Umansky SR. Plasma microRNA biomarkers for detection of mild cognitive impairment: biomarker validation study. Aging (Albany NY). 2013; 5:925-38. https://doi.org/10.18632/aging.100624 PMID:24368295

126. Sheinerman KS, Tsivinsky VG, Crawford F, Mullan MJ, Abdullah L, Umansky SR. Plasma microRNA biomarkers for detection of mild cognitive impairment. Aging (Albany NY). 2012; 4:590-605. https://doi.org/10.18632/aging.100486 PMID:23001356

127. Shan BQ, Li W, He H, Zhao HY, Tian ML, Cheng X, Qin $\mathrm{JB}$, Jin GH. miR-33-3p Regulates PC12 Cell Proliferation and Differentiation In Vitro by Targeting Slc29a1. Neurochem Res. 2021; 46:2403-14. https://doi.org/10.1007/s11064-021-03377-z PMID:

128. Qian Z, Chang J, Jiang F, Ge D, Yang L, Li Y, Chen H, Cao $X$. Excess administration of miR-340-5p ameliorates spinal cord injury-induced neuroinflammation and apoptosis by modulating the P38-MAPK signaling pathway. Brain Behav Immun. 2020; 87:531-42. https://doi.org/10.1016/i.bbi.2020.01.025 PMID: 22014577

129. Zheng $Y$, Zhao $P$, Lian $Y$, Li S, Chen Y, Li L. MiR340-5p alleviates oxygen-glucose deprivation/ reoxygenation-induced neuronal injury via PI3K/Akt activation by targeting PDCD4. Neurochem Int. 2020; 134:104650. https://doi.org/10.1016/j.neuint.2019.104650 PMID: $\underline{31870893}$

130. Zhou W, Huang G, Ye J, Jiang J, Xu Q. Protective Effect of miR-340-5p against Brain Injury after Intracerebral Hemorrhage by Targeting PDCD4. Cerebrovasc Dis. 2020; 49:593-600. 
https://doi.org/10.1159/000508210

PMID:33176298

131. Goswami S, Banerjee A, Kumari B, Bandopadhyay B, Bhattacharya N, Basu N, Vrati S, Banerjee A. Differential Expression and Significance of Circulating microRNAs in Cerebrospinal Fluid of Acute Encephalitis Patients Infected with Japanese Encephalitis Virus. Mol Neurobiol. 2017; 54:1541-51. https://doi.org/10.1007/s12035-016-9764-y PMID:26860411

132. Fu $Y, H u ~ X$, Zheng $C$, Sun $G, X u$ J, Luo S, Cao $P$. Intrahippocampal miR-342-3p inhibition reduces $\beta$ amyloid plaques and ameliorates learning and memory in Alzheimer's disease. Metab Brain Dis. 2019; 34:1355-63.

https://doi.org/10.1007/s11011-019-00438-9 PMID:31134481

133. Montag J, Hitt R, Opitz L, Schulz-Schaeffer WJ, Hunsmann G, Motzkus D. Upregulation of miRNA hsa-miR-342-3p in experimental and idiopathic prion disease. Mol Neurodegener. 2009; 4:36.

https://doi.org/10.1186/1750-1326-4-36

PMID:19712440

134. Wang LL, Min L, Guo QD, Zhang JX, Jiang HL, Shao S, Xing JG, Yin LL, Liu JH, Liu R, Guo SL. Profiling microRNA from Brain by Microarray in a Transgenic Mouse Model of Alzheimer's Disease. Biomed Res Int. 2017; 2017:8030369.

https://doi.org/10.1155/2017/8030369

PMID:29057267

135. Wu DM, Wang S, Wen X, Han XR, Wang YJ, Shen M, Fan SH, Zhuang J, Zhang ZF, Shan Q, Li MQ, Hu B, Sun $\mathrm{CH}$, et al. Suppression of microRNA-342-3p increases glutamate transporters and prevents dopaminergic neuron loss through activating the Wnt signaling pathway via p21-activated kinase 1 in mice with Parkinson's disease. J Cell Physiol. 2019; 234:9033-44.

https://doi.org/10.1002/jcp.27577

PMID:30362546 Retraction in: J Cell Physiol. 2021. [Epub ahead of print].

https://doi.org/10.1002/jcp.30519

PMID:34287853

136. Gonçalves TF, Piergiorge RM, Dos Santos JM, Gusmão J, Pimentel MMG, Santos-Rebouças CB. Network Profiling of Brain-Expressed X-Chromosomal MicroRNA Genes Implicates Shared Key MicroRNAs in Intellectual Disability. J Mol Neurosci. 2019; 67:295-304.

https://doi.org/10.1007/s12031-018-1235-7

PMID:30604382
137. Juźwik CA, Drake $S$, Lécuyer MA, Johnson RM, Morquette $B$, Zhang $Y$, Charabati $M$, Sagan SM, Bar-Or A, Prat A, Fournier AE. Neuronal microRNA regulation in Experimental Autoimmune Encephalomyelitis. Sci Rep. 2018; 8:13437. https://doi.org/10.1038/s41598-018-31542-y PMID:30194392

138. Xu Z, Asahchop EL, Branton WG, Gelman BB, Power C, Hobman TC. MicroRNAs upregulated during HIV infection target peroxisome biogenesis factors: Implications for virus biology, disease mechanisms and neuropathology. PLoS Pathog. 2017; 13:e1006360.

https://doi.org/10.1371/journal.ppat.1006360 PMID:28594894

139. Zhao X, Wu J, Zheng M, Gao F, Ju G. Specification and maintenance of oligodendrocyte precursor cells from neural progenitor cells: involvement of microRNA-7a. Mol Biol Cell. 2012; 23:2867-78.

https://doi.org/10.1091/mbc.E12-04-0270 PMID:22696677

140. Piwecka $M$, Glažar $P$, Hernandez-Miranda $L R$, Memczak S, Wolf SA, Rybak-Wolf A, Filipchyk A, Klironomos F, Cerda Jara CA, Fenske P, Trimbuch T, Zywitza V, Plass $\mathrm{M}$, et al. Loss of a mammalian circular RNA locus causes miRNA deregulation and affects brain function. Science. 2017; 357:eaam8526. https://doi.org/10.1126/science.aam8526 PMID:28798046

141. Jiang S, Yan W, Wang SE, Baltimore D. Dual mechanisms of posttranscriptional regulation of Tet2 by Let-7 microRNA in macrophages. Proc Natl Acad Sci U S A. 2019; 116:12416-21. https://doi.org/10.1073/pnas.1811040116 PMID:31160465

142. Wood SH, van Dam S, Craig T, Tacutu R, O'Toole A, Merry BJ, de Magalhães JP. Transcriptome analysis in calorie-restricted rats implicates epigenetic and post-translational mechanisms in neuroprotection and aging. Genome Biol. 2015; 16:285.

https://doi.org/10.1186/s13059-015-0847-2 PMID:26694192 